\title{
Correction to: Research on Design Process of Small Intangible Cultural Heritage Art Gallery Based on VRP-MUSEUM Technology-Taking the Art Gallery of Shanghai Style Lacquerware as an Example
}

Jingyi Ji, Jianxin Cheng, and Rongrong Fu

\begin{abstract}
Correction to:
Chapter "Research on Design Process of Small Intangible Cultural Heritage Art Gallery Based on VRP-MUSEUM Technology - Taking the Art Gallery of Shanghai Style Lacquerware as an Example" in: C. Stephanidis (Ed.): HCI International 2019 - Posters, CCIS 1034, https://doi.org/10.1007/978-3-030-23525-3_77
\end{abstract}

In the original version of the chapter titled "Research on Design Process of Small Intangible Cultural Heritage Art Gallery Based on VRP-MUSEUM TechnologyTaking the Art Gallery of Shanghai Style Lacquerware as an Example", the given name of the corresponding author and the affiliations of the authors were corrected. 